\title{
AUDIODESCRIÇÃO NA INTERVENÇÃO PEDAGÓGICA DAS DIFICULDADES DE APRENDIZAGEM
}

\author{
Audiodescription in pedagogical intervention of learning difficulties
}

\section{Audiodescripción en la intervención pedagógica de las dificultades de aprendizaje}

\author{
Ana Cláudia Oliveira Pavão * \\ Sílvia Maria de Oliveira Pavão **
}

\begin{abstract}
Resumo
As dificuldades de aprendizagem consistem em obstáculos enfrentados ao aprender e estão presentes desde a Educação Básica até o Ensino Superior. Pelo fato dos sujeitos com dificuldades de aprendizagem não terem sido contemplados pela Política Nacional de Educação Especial, muitas vezes ficam sem receber materiais didáticos e recursos que auxiliem a minimizar suas limitações. $\mathrm{O}$ crescente uso das Tecnologias da Informação e Comunicação em todos os setores da sociedade faz com que professores utilizem cada vez mais vídeos e imagens em suas aulas, muitas vezes sem a presença de recursos acessíveis, destinados às pessoas com deficiência e dificuldades de aprendizagem. Dentre as possibilidades que podem auxiliar os alunos, destaca-se a audiodescrição. Desse modo, esse artigo tem como objetivo discutir a aplicação da audiodescrição na intervenção das dificuldades de aprendizagem. Optou-se por uma revisão integrativa, realizando uma análise crítica da literatura sobre o tema, que reúne dois eixos, dificuldades de aprendizagem e audiodescrição como recurso de acessibilidade. Os resultados apontam a falta de formação de audiodescritores; a formação do professor; e a necessidade de instituir/emergir uma nova cultura envolvendo o entendimento sobre a aprendizagem e a inserção de recursos mediadores.
\end{abstract}

PALAVRAS-CHAVE: Dificuldades de Aprendizagem. Recursos de Acessibilidade. Audiodescrição

\begin{abstract}
Learning difficulties consist in obstacles faced in learning and are present from Basic Education to Higher Education. Because subjects with learning difficulties were not included by the National Policy of Special Education, they often do not receive didactic material and resources that help to minimize their limitations. The increasing usage of Information and Communication Technologies in all sectors of society makes teachers use more and more videos and images on their classrooms often without accessible resources destined to people with disabilities and learning difficulties. Among the possibilities that can help students, the audio description stands out. In this way, this article aims to discuss audio description's application in the intervention of learning difficulties. An integrative review was chosen, making a critical literature analysis regarding the theme, which combines two axes, learning difficulties and audio description as an accessibility resource. The results point out that the lack of training of audiodescribers; teacher training; and the need to institute a new culture involving the understanding about learning and the insertion of mediating resources.
\end{abstract}

\footnotetext{
*Doutora em Informática na Educação. Docente na Universidade Federal de Santa Maria. Email: anaclaudiaoliveira.pavao@gmail.com. Orcid: https://orcid.org/0000-0002-9914-3700

** Pós-Doutora em Educação. Docente na Universidade Federal de Santa Maria. Email: silviamariapavao@gmail.com. Orcid: https://orcid.org/ 0000-0002-5365-0280
} 
KEYWORDS: Learning Difficulties. Accessibility Resources. Audio Description

\section{Resumen}

Las dificultades de aprendizaje consisten en obstáculos enfrentados al aprender y están presentes desde la Educación Básica hasta la Enseñanza Superior. Por el hecho de los sujetos con dificultades de aprendizaje no seren contemplados por la Política Nacional de Educación Especial, muchas veces quedan sin recibir materiales didácticos y recursos que ayuden a minimizar sus limitaciones. El crescente uso de las Tecnologías da Información y Comunicación en todos los setores de la sociedad hace con que profesores utilicen cada vez más vídeos e imágenes en sus clases, a menudo sin la presencia de recursos accesibles, destinados a las personas con deficiencia y dificultades de aprendizaje. Entre las posibilidades que pueden auxiliar a los alumnos, se destaca la audiodescripción. De este modo, este articulo tiene como objetivo discutir la aplicación de la audiodescripción en la intervención de las dificultades de aprendizaje. Se optó por una revisión integrativa, realizando un análisis crítico de la literatura sobre el tema, que reúne dos ejes, dificultades de aprendizaje y audiodescripción como recurso de accesibilidad. Los resultados apuntan la falta de formación de audiodescriptores; la formación de profesor; y la necesidad de instituir/emerger una nueva cultura que envolucra la compreensión sobre el aprendizaje y la inserción de recursos mediadores.

PALABRAS CLAVE: Dificultades de Aprendizaje. Recursos de Accesibilidad. Audiodescripción

\section{INTRODUÇÃO}

Esse estudo trata do processo de aprendizagem, mais especificamente, da aprendizagem e da contribuição da audiodescrição, como recurso de acessibilidade, face às dificuldades de aprendizagem.

A aprendizagem como processo, está presente em todas as etapas da vida do ser humano, mas é na fase em que a criança ingressa na escola, para iniciar o processo de escolarização que as dificuldades para o aprender se evidenciam. Isso porque ao ingressar no ensino formal, a criança deve atender a uma série de regras, compreender as diferenças do sistema escolar que está inserida, entre tantas outras aprendizagens. Nesse sentido, se entende que aprender não implica em um evento puramente individual, mas em consonância com o tempo, história e cultura do lugar que as pessoas estão inseridas.

Desse modo, as dificuldades de aprendizagem no processo de escolarização, podem surgir em decorrência de fatores emocionais, orgânicos e contextuais. Essa concepção de que as dificuldades de aprendizagem não estão centradas nos sujeitos, tem base explicativa em teorias do desenvolvimento e aprendizagem de abordagem interacionistas (PIAGET, 1986, 2009; VYGOTSKY, 1984). O fracasso na aprendizagem pode ser resultante de fatores provenientes dessa relação entre sujeitos e objetos do conhecimento. Uma análise desse fracasso pode ser empreendida a partir de três principais ideologias: "a ideologia do dom, a da deficiência cultural e a das diferenças culturais" (OLIVEIRA; SANTOS; ASPILICUETA, 2012, p. 105). No primeiro caso, a explicação centra a causa do mérito ou fracasso no sujeito, e nas duas últimas, ainda que remeta a causas externas, condiciona a capacidade do sujeito de aprender ou não, pois os sujeitos não aprendem justamente, pela diferença cultural e social menos privilegiada.

Para compreender o processo de aprender e as causas dos problemas de aprendizagem, se entende que o sujeito que aprende e o objeto de conhecimento, em uma relação que não 
podem ser dados como separados, pois, quando as dificuldades de aprendizagem ocorrem, de acordo com Paín (1985) uma análise apurada de condições internas e externas deve ser procedida, incluindo três dimensões na condição interna, que abarcam o corpo como infraestrutura neurofisiológica, a condição cognitiva da aprendizagem, e as aptidões do sujeito. Já as condições externas são aquelas que definem o campo de estímulo (oportunidades, amplo contex to experiencial).

Geralmente na ocorrência de dificuldades ou problemas de aprendizagem, são analisados, sob diferentes perspectivas, os fatores: maturidade afetiva, inteligência, motricidade, percepção e problemas pedagógicos. Alguns fatores para melhor fluir esse aprender podem ser cruciais. Tomando para efeito de análise que aprender implica na relação do sujeito com o meio, se deve considerar as ferramentas que podem colaborar para que essa relação, entre o sujeito e os objetos de aprendizagem, possa ocorrer com o melhor desempenho possível.

Dentre as questões que devem ser consideradas para contribuir com a aprendizagem dos alunos está a acessibilidade dos materiais e recursos utilizados no processo de ensino e aprendizagem, entendida nesse estudo como "a possibilidade e condição de alcance para utilização, com segurança e autonomia [...]” (BRASIL, 2015).

Frente ao desenvolvimento e utilização das Tecnologias de Informação e Comunicação-TIC na sociedade atual, houve um crescimento dos recursos de acessibilidade, provenientes das TIC, e uma demanda na oferta de possibilidades que permitam condições de autonomia e desenvolvimento de todos os sujeitos.

Para tal, a audiodescrição é conceituada como um recurso de acessibilidade, conforme a Portaria 188, " é a narração, em língua portuguesa, integrada ao som original da obra audiovisual, contendo descrições de sons e elementos visuais e quaisquer informações adicionais que sejam relevantes para possibilitar a melhor compreensão." (BRASIL, 2010 art. $\left.1^{\circ}\right)$

A audiodescrição como recurso de acessibilidade está em expansão em suas atividades e tem ocupado um lugar de destaque, "com a regulamentação do Decreto $n^{0}$ 5296, que determina sua obrigatoriedade na televisão aberta brasileira, vigorando desde 2012" (MIANES, 2016, p. 11). Somado a isso, mais recentemente o Decreto ${ }^{\circ}$ 9.404, determina que "as salas de espetáculo deverão dispor de meios eletrônicos que permitam a transmissão de subtitulação, por meio de legenda oculta e de audiodescrição [...] (BRASIL, 2018, art. $6^{\circ}$ ).

Nesse contexto, a problemática que guiou a presente investigação busca responder: como a audiodescrição, como recurso de acessibilidade, pode colaborar para o desenvolvimento da aprendizagem?

Diante disso, o objetivo desse estudo consiste em discutir a aplicação da audiodescrição na intervenção das dificuldades de aprendizagem.

\section{Método}

A fim de alcançar os objetivos propostos que foram pautados pela análise crítica da literatura sobre o tema, que reúne dois grandes eixos -dificuldades de aprendizagem e audiodescrição- a pesquisa utilizou a revisão integrativa, em consonância com Mendes; Silveira \& Galvão (2008). As etapas do método de revisão buscaram atender ao rigor 
científico desse tipo de pesquisa, em que Mendes; Silveira \& Galvão (2008) e Souza; Silva \& Carvalho (2010) abordam seis etapas: Figura 1

\begin{tabular}{|c|c|}
\hline Etapas do método & Descrição \\
\hline 1 identificando o tema e a hipótese & $\begin{array}{l}\text { Tema: dificuldades de aprendizagem e } \\
\text { audiodescrição. } \\
\text { Hipótese: a audiodescrição é um recurso de } \\
\text { acessibilidade para as pessoas com dificuldades } \\
\text { de aprendizagem. }\end{array}$ \\
\hline $\begin{array}{l}2 \text { Critérios para inclusão e exclusão de estudos/ } \\
\text { amostragem ou busca na literatura }\end{array}$ & $\begin{array}{l}\text { Estudos diversos sobre as temáticas (artigos, } \\
\text { livros) } \\
\text { Estudos com variadas metodologias (de campo } \\
\text { ou teórico) } \\
\text { Legislação ou documentação legal sobre } \\
\text { audiodescrição (Políticas, Leis, Portarias, } \\
\text { Decretos, Normativas) }\end{array}$ \\
\hline 3 Elementos extraídos dos estudos selecionados & Conceitos, descrições, teorias \\
\hline $\begin{array}{l}4 \text { Avaliação dos estudos incluídos na revisão } \\
\text { integrativa }\end{array}$ & $\begin{array}{l}\text { Considerando a carência de estudos que } \\
\text { relacionem dificuldades de aprendizagem a } \\
\text { audiodescrição, foram utilizados todos os que } \\
\text { continham os descritores (aprendizagem e } \\
\text { audiodescrição). Considerar nessa análise que a } \\
\text { audiodescrição foi originalmente desenvolvida } \\
\text { para o uso com pessoas com deficiência visual. }\end{array}$ \\
\hline 5 Interpretação & Abordagem qualitativa \\
\hline $\begin{array}{llll}6 & \text { Apresentação } & \text { da } & \text { revisão/síntese } \\
\text { conhecimento. }\end{array}$ & Abordagem explicativa e descritiva \\
\hline
\end{tabular}

Fonte: As autoras

\section{Desempenho na aprendizagem}

A aprendizagem se constitui em um processo que ocorre no decorrer de toda a vida, razão pela qual se deve estar permanentemente em processo de discussão. A escola é a instituição social que legitima as aprendizagens formais. Agentes do processo escolar e família são fundamentais nesse processo, "a congruência entre família e escola e as regularidades sociais desta mesma escola são de grande impacto na interação e na aprendizagem"

Quando esse processo ocorre de forma fluídica, ou sem obstáculos, resulta o bom rendimento e desempenho escolar. Diz-se que a aprendizagem ocorreu. Mas, nem sempre esse processo, ocorre sem obstáculos, e as dificuldades de aprendizagem passam a vigorar.

Durante os primeiros anos do processo de escolarização, a criança poderá enfrentar problemas de ordem emocional, cognitiva ou motora. Os problemas emocionais, podem ser decorrentes de diversos fatores. $\mathrm{O}$ sujeito acometido por tais dificuldades, geralmente tem afetada sua estima e consequentemente intensifica os problemas para aprender. Crianças, jovens ou adultos que enfrentam dificuldades para aprender, refletem essas dificuldades em 
todos os espaços que participam (escola, família ou trabalho), pois o ambiente tem influência na construção do conhecimento.

O desempenho da aprendizagem escolar pode ser afetado levando a um baixo rendimento acadêmico, e levando ao fracasso e a reprovação, nesse momento se instauram as dificuldades de aprendizagem, que são provenientes de fatores tanto externos, que dizem respeito ao meio, interno que repercutem na ação do sujeito, e também de causas orgânicas. A manifestação das dificuldades pode ser em diferentes etapas do desenvolvimento do sujeito, sendo desencadeados por causa relacionadas à organização escolar, planejamento didático, perfil do professor, personalidade, entre outros. Em síntese, os fatores que incidem sobre os problemas de aprendizagem são de natureza orgânica, específicos, psicológico e ambientais.

São problemas de aprendizagem específicos os relacionados à: linguagem (dislalia), leitura (dislexia), escrita (disgrafia) e matemática (discalculia). Esses problemas são considerados específicos, pois implicam em afetações também orgânicas nas causas da manifestação, isto é, existem indicativos de comprometimento orgânicos na área das agnosias (percepção). Assim, várias são as manifestações do não aprender que incitam intervenção pedagógica. Essas intervenções podem ocorrer na escola, ou contando com uma rede de suporte (outros profissionais que possam fazer $\mathrm{o}$ atendimento as necessidades de aprendizagem).

À busca por minimizar esses problemas é caracterizada pelo apoio especializado. Especialistas de diferentes áreas do conhecimento, constituem uma rede de apoio para o enfrentamento dos problemas de aprendizagem. Diferentes alternativas, dependendo do tipo de dificuldade e área afetada são buscadas para que as dificuldades sejam superadas. Mas, o que se deve levar em conta na intervenção dos especialistas, "é o sujeito em sua dimensão única. Esse é o ponto de ligação do grupo de diferentes campos disciplinares e perspectivas teóricas" (ROTTA; BRIDI FILHO; BRIDI, 2018, p. 313),

Dificuldades de aprendizagem podem ocorrer em qualquer etapa da vida, e não somente nos anos iniciais do processo de escolarização, sendo necessária a intervenção pedagógica. Especialistas de diferentes áreas do conhecimento, vem desenvolvendo e aplicando metodologias e técnicas, com vistas a diminuir essas dificuldades. Grande parte dessas técnicas e metodologias envolvem os aspetos psicopedagógicos, sendo utilizados elementos de natureza lúdica, ampla variedade de jogos, atividades que abordem todas as dificuldades apresentadas, atividades baseadas na leitura, escrita, raciocínio matemático e concentração. No entanto, o não atendimento a essas questões, de modo acessível, poderá comprometer o desempenho escolar do sujeito com dificuldades de aprendizagem, apresentando obstáculos que possivelmente irão interferir no seu desenvolvimento.

Considerando que a Política Nacional de Educação Especial na Perspectiva da Educação Inclusiva não contempla, como público alvo da educação especial, os sujeitos com dificuldades de aprendizagem, ao mesmo tempo propõe uma escola inclusiva, em que todos os alunos devem ter acesso a materiais e recursos, em condições de igualdade. Portanto, tendo em vista a presença de alunos com dificuldades de aprendizagem não específicas, na sala de aula, o professor, ou profissionais de apoio ao ensino, poderão lançar mão do uso dos recursos da audiodescrição.

\section{Audiodescrição como recurso de acessibilidade aos alunos com dificuldades de aprendizagem}


A sociedade contemporânea, marcada pelo uso crescente das Tecnologias de Informação e Comunicação-TIC, utiliza cada vez mais a Internet e suas possibilidades, para realizar atividades cotidianas, estudo, lazer e comunicação. Pelo fato de poder incluir diversos tipos de mídia, a Internet tem como atrativo, o uso de vídeos e imagens em movimento ou estáticas, que, muitas vezes, ao não poderem ser vistas, impedem o usuário de compreender o que tem que ser realizado ou o significado da mensagem que está recebendo.

Sob a perspectiva do uso das TIC na educação, a partir da implantação da Política Nacional de Educação Especial na Perspectiva da Educação Inclusiva, em 2008, os temas em torno da inclusão e, por conseguinte, das TIC, como recursos de acessibilidade, têm sido pauta dos debates educacionais, devido à diversidade de alunos presentes na sala de aula regular. Esse cenário, propõe o repensar das práticas da sala de aula, o que remete ao planejamento didático diferenciado, com estratégias pedagógicas acessíveis, evidenciando as imagens, em especial para os estudantes com deficiência visual, mas também para aqueles com dificuldades de aprendizagem (MOTTA, 2016).

Nesse sentido, é necessário que sejam disponibilizados recursos de acessibilidade a todos os alunos que deles necessitem, para que possam usufruir com equidade os materiais pedagógicos utilizados pelos professores.

Dentre os recursos de acessibilidade, também denominado de tecnologia assistiva-TA, está a audiodescrição, que, muito embora tenha em sua origem, possibilitar descrever em palavras, imagens, vídeos, espetáculos e eventos, para a pessoa cega, tem se mostrado como potencial recurso de acessibilidade aos alunos com dificuldade de aprendizagem, eliminando barreiras comunicacionais. A comunicação é essencial para a aprendizagem e desenvolvimento do ser humano, e a audiodescrição pode ser vista como um "[...] um recurso que, dada a evolução das tecnologias, torna-se imprescindível, é impossível imaginar a vida diária sem ela" [...] (SANT’ANNA, 2010, p. 155), pois se pode comprometer a visão das pessoas em seu contexto relacional.

Bastos (2018), argumenta que estudantes com algum tipo de dificuldade de aprendizagem, conforme suas limitações, necessitam de estratégias e recursos diferenciados, desde a apresentação do conteúdo, avaliação, entre outros do cotidiano escolar, na educação básica, se estendendo até níveis mais elevados, como o ensino superior. As limitações apresentadas pelos sujeitos com dificuldades de aprendizagem no reconhecimento das palavras, por exemplo, obrigam-no, muitas vezes, a realizar uma leitura decifratória, o que torna extremamente difícil, até mesmo a soletração de sílabas e palavras. Nesse esforço em decodificar o material, a velocidade e a compreensão necessárias para a leitura diminuem significativamente (BASTOS, 2018).

Assim, efetivamente a audiodescrição, por apresentar um detalhamento das situações (Fig. 2), pode oferecer às pessoas com dificuldades de aprendizagem, possibilidades de melhor compreender as situações e objetos a serem aprendidos. As pessoas que apresentam dificuldade, em geral precisam, contar com um tempo de estudo ampliado, bem como, no que tange aos aspectos cognitivos, favorecer processo de atenção, memória, linguagem, raciocínio entre outros.

Figura 2 - Exemplo de fragmento de uma audiodescrição

[...] Filme Estrangeiro: Neste caso, as falas dos personagens precisam estar completas e identificadas, pois também serão lidas pelos atores audiodescritores.

Trecho do roteiro de audiodescrição e voice over para o filme Los Olvidados de Luis Buñuel.

AD: Um grupo de jovens de diferentes idades faz uma brincadeira em um terreno urbano desocupado entre prédios. Ao fundo um prédio em ruínas. Em primeiro plano um muro de pedras e madeira 


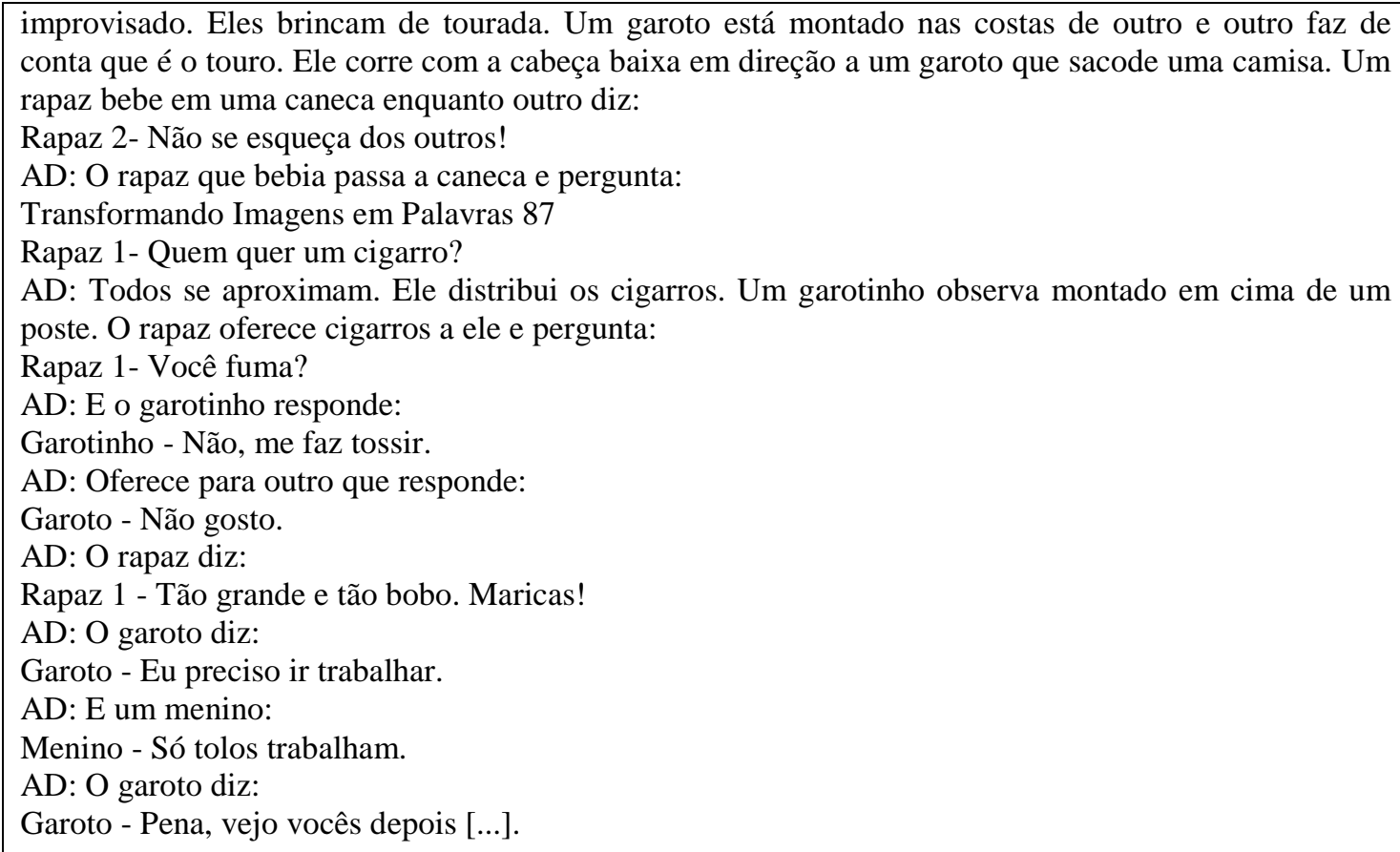

Fonte: MOTTA; ROMEU FILHO (2010, p.86-7).

A audiodescrição parece ofertar, do mesmo modo, condições para que o sujeito possa decifrar os signos do objeto a ser aprendido e internalizar informações, transformando-os em conhecimento. Motta (2010, p.2) argumenta que "Mesmo as pessoas sem deficiência têm notado que o recurso aumenta o senso de observação, amplia a percepção e o entendimento, mostra e desvela detalhes que passariam despercebidos".

Para Motta e Romeu Filho (2010), tem havido uma crescente demanda do público que necessita de audiodescrição, talvez não apenas pelo aumento de pessoas cegas, mas pela experiência com públicos que possuem "dificuldades de compreensão de audiovisuais e leitura de textos contidos em imagens". Para atender aos diferentes públicos e contextos em que é necessária a audiodescrição, Pozzobon (2016) classifica em quatro tipos: 1) gravada, na qual é elaborado um roteiro, que após é gravado e sincronizado; 2) ao vivo ensaiada, utilizada em peças e espetáculos de dança, óperas e manifestações artísticas. Embora o roteiro seja ensaiado, a execução é ao vivo, ao mesmo tempo em que a obra é exibida; 3) audiodescrição simultânea, é utilizada em eventos transmitidos ao vivo; e 4) audiodescrição em filmes estrangeiros não-dublados, utilizada para descrever cenas silenciosas ou apenas com som, nesse caso não é dublagem, pois não há interpretação.

Entretanto, Sant'Anna (2010), argumenta que para além do tipo e finalidade a que se destina a audiodescrição, ela deve servir para propiciar a participação plena dos sujeitos com deficiência, em todos os contextos sociais, "Seja na televisão, teatro, cinema ou mesmo nas descrições de gráficos e figuras de um livro, ou imagens de uma página da internet, ela é fundamental para a participação efetiva das pessoas com deficiência na interação com a sociedade" (p.155).

Embora as dificuldades de aprendizagem não sejam consideradas uma deficiência, segundo a Política Nacional, nos contextos educacionais, onde se utilizam materiais pedagógicos, como filmes, imagens e eventos culturais é necessário que se utilize a 
audiodescrição, como já é utilizada em contextos sociais, de modo a eliminar ou diminuir as barreiras comunicacionais dos sujeitos com dificuldades de aprendizagem. Silva e Michels (2015) chamam atenção para o fato das escolas utilizarem vídeos educativos e materiais didáticos com imagem, sem audiodescrição e de não possuírem professores com essa formação, para auxiliar outros professores do ensino regular, perante essa necessidade.

Do mesmo modo, Mianes (2013), ao tratar da importância da utilização da audiodescrição no contexto educacional, ressalta o fato desse recurso não estar presente nas grades curriculares dos cursos de formação de professores. Isso dificulta também a formação de audiodescritores, limitando, assim, os materiais audiodescritos e elevando os preços desse serviço.

Diante dessa realidade, os sujeitos que seriam beneficiados pelo recurso, perdem a possibilidade de compreender e avançar em muitos aspectos do desenvolvimento escolar, muitas vezes, não pelas dificuldades que possuem, mas porque lhes faltam condições adequadas de apresentação dos materiais didáticos.

Nessa perspectiva, Motta (2015) insere a audiodescrição como um instrumento de mediação, que pode auxiliar os alunos a fazerem inferências, deduções e chegarem a conclusões, argumentando que o desenvolvimento e a aprendizagem infantil ocorre em um contexto social e cultural por meio da linguagem, mas não são resultantes apenas das informações sensoriais, "mas sim quando associamos e aprendemos os significados atribuídos aos símbolos e códigos social e culturalmente construídos" (MOTTA, 2015, p. 7).

Sobre mediação e atribuição de significados, Bastos (2018) ao realizar estudos com alunos com dificuldades de aprendizagem, que frequentam o ensino superior, se deparou com a presença de alunos que, em função da limitação, reconhecem as letras, fazem algumas relações com o som (grafema/fonema) formando algumas sílabas, mas têm muita dificuldade na formação das palavras, não realizando a leitura de frases e textos. Outros, ainda apresentam grande dificuldade de interpretação e concentração, necessitando de releitura e mais tempo para compreensão.

Quando a audiodescrição tem finalidade didática, enquanto recurso de mediação para a acessibilidade do aluno, Vergara Nunes (2016), diferencia a audiodescrição padrão, que possui descrição objetiva e 'neutra' e a audiodescrição didática, com interpretação e informações agregadas. Além disso, o autor apresenta diretrizes para a produção de roteiros de audiodescrição didática, com a intuito de compartilhar o conhecimento entre os sujeitos. Embora o estudo tenha sido destinado a alunos cegos e com baixa visão, entende-se igualmente adequado na perspectiva do aluno com dificuldades de aprendizagem, pois os detalhes das informações contidas na audiodescrição, podem contribuir com a mediação entre a dificuldade de leitura do aluno e o significado nela contido.

Nesse caso, "o sujeito que aprende por meio de recursos de visualização do conhecimento audiodescritos e o sujeito que os traduz de uma linguagem visual para uma linguagem verbal estabelecem uma relação de confiança no contexto da aprendizagem; este se torna o mediador do conhecimento explicitado para aquele" (VERGARA NUNES, 2016, p. 66). Essa explicação, a riqueza dos detalhes dos conteúdos trabalhados com os sujeitos com dificuldades de aprendizagem, em muitas vezes, é feita pelo próprio professor, por um colega ou até mesmo por familiar. No caso do uso da audiodescrição, o aluno conquista autonomia em qualquer espaço e tempo, não dependendo de outros, para interagir com o material e apreender seu significado.

Portanto, os contextos educacionais, independentemente do nível de ensino, devem estar preparados para disponibilizar materiais e conteúdos didáticos acessíveis e que 
efetivamente, possam contemplar as necessidades e contribuir com a aprendizagem, desenvolvimento e autonomia do aluno e, nesse sentido, a audiodescrição se configura como um recurso de acessibilidade, imprescindível, ao aluno com dificuldades de aprendizagem.

\section{CONSIDERAÇÕES FINAIS}

O presente trabalho objetivou discutir a aplicação da audiodescrição na intervenção das dificuldades de aprendizagem. Com isso, a importância de conhecer a utilização da audiodescrição, especialmente no âmbito escolar, pois os problemas de aprendizagem que afetam as pessoas, podem ser minimizados com o uso desse recurso.

Os problemas de aprendizagem, por serem originados de causas diversas e nem sempre de fácil identificação, pois surgem em qualquer etapa do desenvolvimento e tendem a serem grandes obstáculos para o crescimento e desenvolvimento das pessoas, que necessitam de uma assertiva intervenção pedagógica.

Muito embora, esses problemas de aprendizagem sejam geralmente compreendidos como responsabilidade do sujeito, se sabe que o aprender, depende da interação do sujeito com o meio e, em assim sendo, os fatores cognitivo, afetivo, motor e social estão implicados.

Portanto, a discussão de alternativas para o desenvolvimento da aprendizagem precisa ser uma busca continua dos agentes educacionais. Nesse aspecto, as TIC trazem contribuições relevantes à utilização de recursos, metodologias e materiais didáticos acessíveis. Considerando os sujeitos que apresentam dificuldades de aprendizagem, a utilização da audiodescrição apresenta-se como recurso acessível, que possibilita a eliminação de barreiras comunicacionais e possibilita a apreensão do mundo, seus códigos, sentidos e significados.

Entendendo-se que a audiodescrição, originalmente, foi pensada para atender às pessoas cegas, é notório o benefício que pode trazer às pessoas com dificuldades de aprendizagem, pelo fato de detalhar aspectos dos objetos a serem aprendidos, favorecendo a aprendizagem.

No entanto, é preciso considerar que o estudo desenvolvido, visando a utilização da audiodescrição com alunos que apresentam dificuldades de aprendizagem, é um trabalho que merece ainda percorrer outros caminhos, na escola e na sociedade. Dentre esses, destaca-se que a formação de audiodescritores para atender à demanda no campo da educação e em outros contextos sociais, é apenas uma etapa para a disseminação e produção de materiais audiodescritos. Equivale-se a essa etapa, em termos de importância, a formação do professor para utilizar e compreender os inúmeros benefícios que recursos audiodescritos trazem às pessoas com dificuldades de aprendizagem. Somando-se a essas duas questões, percebe-se a necessidade de instituir/emergir uma nova cultura, que envolve não só o entendimento sobre a aprendizagem dos sujeitos que apresentam dificuldades, como a inserção de recursos mediadores, que possam minimizar as barreiras e contribuir com as potencialidades de cada aluno.

Sendo assim, o estudo realizado pretende colaborar para que a utilização da audiodescrição potencialize processos de boas práticas didáticas, junto aos professores e alunos com dificuldades de aprendizagem, permitindo que, para além dos objetivos traçados nesse estudo, se promova a equidade na educação e a autonomia dos sujeitos. Por fim, o conhecimento, a compreensão, a valorização dos suportes fundamentais para se obter êxito na aprendizagem, podem contar com o recurso da audiodescrição. 


\section{REFERÊNCIAS}

BASTOS, Liziane Forner. O Uso das TIC na Promoção da Acessibilidade de Estudantes Disléxicos na UFSM. Dissertação de Mestrado. Universidade Federal de Santa Maria, Santa Maria, RS, 2018. 126p.

BRASIL. Decreto $n^{o}$ 9.404, de 11 de junho de 2018. Disponível em: < http://www.planalto.gov.br/ccivil_03/_Ato2015-2018/2018/Decreto/D9404.htm> Acesso em: 24 out. 2018.

BRASIL. Portaria $n^{o}$ - 188, de 24 de março de 2010. Disponível em: < http://www.anatel.gov.br/legislacao/normas-do-mc/443-portaria-188> Acesso em: 24 out. 2018.

CARPES, Daiana Stockey. (Org.) Audiodescrição: práticas e reflexões [recurso eletrônico] / Organizadora- Santa Cruz do Sul: Catarse, 2016. 165 p. Texto eletrônico. Disponível em: http://www.ufpb.br/cia/contents/manuais/livro-audiodescricao-praticas-e-reflexoes.pdf Acesso em: 26 nov. 2016.

JAKOBSON, R. Lingüística e teoria da comunicação. São Paulo: Cultrix, 1995.

MIANES, Felipe Leão. Consultoria em audiodescrição: alguns caminhos e possibilidades. In: CARPES, Daiana Stockey. (Org.) Audiodescrição: práticas e reflexões [recurso eletrônico] / Organizadora- Santa Cruz do Sul: Catarse, 2016. 165 p. Texto eletrônico. Disponível em: <http://www.ufpb.br/cia/contents/manuais/livro-audiodescricao-praticas-e-reflexoes.pdf >Acesso em: 26 nov. 2018.

MIANES, Felipe Leão. A importância da audiodescrição na sala de aula. Entrevista ao Portal Terra, (2013). Disponível em: <https://matavunesp.wordpress.com/2013/09/01/a-importanciada-audiodescricao-na-sala-de-aula/ $\geq$ Acesso em: 26 nov. 2018.

MENDES, K.D.S., SILVEIRA, R.C.C.P. \& GALVÃO, C.M. Revisão integrativa: método de pesquisa para incorporação de evidências na saúde e na enfermagem. Revista Texto e Contexto-Enfermagem, 2008. 17(4), 758-764. Doi: 10.1590/S0104-07072008000400018.

MOTTA, Lívia Maria Villela de Mello; ROMEU FILHO, Paulo. Transformando imagens em palavras. São Paulo: Secretaria dos Direitos das Pessoas com Deficiência do Estado de São Paulo, 2010. 
MOTTA, Lívia Maria Villela de Mello. A audiodescrição na escola: abrindo caminhos para leitura de mundo. Campinas: Pontes Editores, 2016.

OLIVEIRA, Jáima Pinheiro de; SANTOS, Sabrina Antunes dos; ASPILICUETA, Patrícia CRUZ, Gilmar de Carvalho. Concepções de professores sobre a temática das chamadas dificuldades de aprendizagem. Rev. Bras. Ed. Esp., Marília, v.18, n.1, p. 93-112, Jan.-Mar., 2012. ISSN 1413-6538. http://dx.doi.org/10.1590/S1413-65382012000100007

PAÍN, Sara. Diagnóstico e tratamento dos problemas de aprendizagem. Porto Alegre: Artes Médicas, 1985.

PIAGET, Jean. A linguagem e o pensamento da criança. Trad. Manuel Campos. São Paulo: Martins Fontes, 1986.

PIAGET, Jean. Seis estudos de psicologia. 24. ed. Rio de Janeiro: Forense, 2009.

POZZOBON, Lara. Entrevista. 2016. Disponível em: <https://verouvindo.com/2016/04/08/verouvindo-entrevista-lara-pozzobon/> Acesso em: 26 nov. 2018.

ROTTA, Newra Tellechea. Transtornos da aprendizagem. Porto Alegre: Artmed, 2006.

ROTTA, N. T.; BRIDI FILHO, C A.; BRIDI, F. R. de S. (Orgs.). Aprendizagem e intervenção terapêutica. In: ROTTA, N. T.; BRIDI FILHO, C A.; BRIDI, F. R. de S. (Orgs.). Plasticidade Cerebral e Aprendizagem. Abordagem Multidisciplinar. Porto Alegre: Artmed, 2018. p. 302-15.

SANT'ANNA, Laércio. A importância da audiodescrição na comunicação das pessoas com deficiência. In: MOTTA, Lívia Maria Villela de Mello; ROMEU FILHO, Paulo. Transformando imagens em palavras. São Paulo: Secretaria dos Direitos das Pessoas com Deficiência do Estado de São Paulo; 2010.

SILVA, Mara Cristina Fortuna da. MICHELS, Lísia Regina Ferreira. A importância de cursos de formação continuada em audiodescrição para professores do Atendimento Educacional Especializado. Revista Brasileira de Tradução Visual-RBTV. v.18, nº18, 2015.

SOUZA, M.T.; SILVA M.D.; CARVALHO, R. Revisão integrativa: o que é e como fazer. Einstein [Internet]. 2010 [cited 2016 Mar 09]; 8(1Pt1): 102-6. Disponível em: <http://www.scielo.br/pdf/eins/v8n1/1679-4508-eins-8-1-0102.pdf[ Links > Acesso em: 24 out. 2018. 
VERGARA-NUNES, Elton. Audiodescrição didática. Tese de doutorado. Universidade Federal de Santa Catarina, Florianópolis, SC, 2016. 412p.

VYGOTSKY, L. S. A formação social da mente. São Paulo. SP: Martins Fontes, 1984.

Recebido em: 17/10/2019

Aprovado em: 19/12/2019 